\title{
Peri-implant health after supportive mucositis therapy is associated with increased levels of FGF-2
}

\begin{abstract}
Juliana Prazeres Gonçalves de Castro (1)1, Telma Regina da Silva

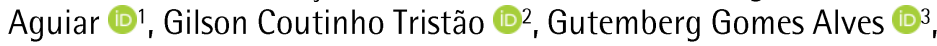
Marina Prado Fernandes Pinheiro (1) 1, Valquiria Quinelato (1) 1, Priscila Ladeira Casado (1)1, George E. Romanos (104.
\end{abstract}

\begin{abstract}
This study aimed to analyze Fibroblast Growth Factor-2 (FGF-2) levels in the peri-implant crevicular fluid throughout supportive mucositis therapy. Twenty-six participants with Branemark protocol prosthesis were divided into two groups: the control group, characterized by healthy peri-implants, and the mucositis group, presenting a diagnosis of peri-implant mucositis. All participants underwent clinical examination, radiographic analysis, prosthesis removal, and non-invasive peri-implant therapy (mechanical debridement associated with chlorhexidine $0.12 \%$ ) during a period of 36 days divided into three intervals. Peri-implant crevicular fluid samples were collected at each interval in order to analyze FGF-2 levels by immuno-enzymatic assay. The control and mucositis groups showed difference in keratinized mucosa. The smaller the range of keratinized mucosa the higher susceptibility of periimplant mucositis. Throughout the treatment intervals, participants were diagnosed in different groups indicating whether or not the non-invasive therapy was able to treat peri-implant mucositis. There was a significant difference of FGF-2 levels between groups, with the higher FGF-2 levels in the control group $(p=0.01)$. After supportive therapy, the mucositis group showed significantly increased FGF-2 levels $(p<0.01)$ compared to initial levels. After 36 days of supportive therapy, there was a reduction of peri-implant mucositis from $70 \%$ to $23 \%$. Clinical and laboratory outcomes showed a clear correlation since FGF-2 levels increased after 36 days. It was concluded that the therapy protocol was effective and promoted a regenerative reaction and FGF-2 can be considered a future target for peri-implant mucositis understanding.
\end{abstract}

\author{
1 Department of Implant Dentistry Post- \\ graduation, Fluminense Federal University - \\ School of Dentistry - Niterói - RJ - Brazil \\ ${ }^{2}$ Department of Clinical dentistry, Fluminense \\ Federal University - School of Dentistry - Niterói \\ - RJ - Brazil \\ ${ }^{3}$ Cellular and Molecular Biology Department, \\ Fluminense Federal University - School of \\ Biology - Niterói - RJ - Brazil \\ ${ }^{4}$ Stony Brook University - School of Dental \\ Medicine - United States
}

Correspondence: Casado, P.L. Address: Mario Santos Braga Street, 28 - Centro - Niterói - RJ Brazil - 24020-140 Tel: +55 (21) 2629-9920; Fax: +55 (21) 2629-9920

E-mail: priscilacasado@id.uff.br

Key Words: Biomarkers;

Crevicular fluid; Dental

Implants; Fibroblast Growth

Factor-2; Mucositis

\section{Introduction}

The use of osseointegrated implants to restore compromised oral function and esthetics after tooth loss is an established treatment modality and has proven to be a routine procedure in oral rehabilitation of edentulous patients, achieving long-term success (1). However, complications associated with inappropriate treatment planning, surgical and prosthetic procedures and peri-implant diseases have increased over the last few years (2).

Peri-implant diseases present in two forms - peri-implant mucositis and peri-implantitis, which are characterized by an exacerbated inflammatory reaction around the implant (3). Reccently, the 2017 World Workshop of the American Academy of Periodontology and European Federation of Periodontology (4) described peri-implant mucositis as an inflammatory lesion of the soft tissues surrounding an endosseous implant in the absence of loss of supporting bone or continuing marginal bone loss. The Consensus report on the Classification of Periodontal and Peri-Implant Diseases and Conditions, in 2018, (5) stated that, there is an increase in probing depth in peri-implant mucositis probably due to swelling or decrease in probing resistance. Moroever, there is strong evidence in the literature, from animal and human researches, that plaque is the etiological factor for peri-implant diseases.

Despite differences regarding the differential diagnosis of peri-implant diseases, studies estimated that mucositis around implants has a prevalence of $64.6 \%$ at patient level (4). In addition, the lack of regular supportive therapy in patients that received implant treatment and were previously diagnosed with peri-implant mucositis is associated with significant increased risk for the conversion of mucositis to peri-implantitis (6). In this context, early detection of peri-implant breakdown, as well as monitoring the bone loss development and progression of peri-implantitis is markedly important (7).As opposed to 
peri-implantitis, mucositis is characterized by a reversible lesion that has the potential of peri-implant tissue recovering shorty after treatment (3).

Despite the variety of clinical procedures described to treat mucositis, there is no consensus on the best treatment option and clinical results. Most of the research and case reports point to noninvasive techniques as the main protocol, including debridement using titanium curettes (8), plastic curettes (9), abrasive air-polishing $(8,10)$, ultrasonic devices $(10)$, and adjunctive use of antimicrobial products $(8,11)$.Recently published research has been focused on the correlation between biochemical markers of inflammation and regeneration and clinical parameters around healthy and diseased implants (12). The peri-implant crevicular fluid (PICF) was shown as a promising medium for the detection of peri-implant activity (13). Levels of biochemical mediators secreted into the PICF were considered diagnostic markers to monitor peri-implant health, reflecting the degree of inflammatory and regenerative reaction affecting the surrounding tissues, bone, and mucosa (7).

Growth factors are a potential agent to target specific tissue reactions because of their regulatory roles in cellular functions, including adhesion, proliferation, migration, and differentiation. They are biological mediators that play critical roles in the stimulation and regulation of wound healing (14). In mammals, the Fibroblast Growth Factor (FGF) family is comprised of 22 structurally related proteins that have a wide variety of functions contributing to organogenesis, tissue remodeling, nervous system control, angiogenesis, and regulation of metabolism. These proteins are structurally related, but with different actions and biological consequences. The fibroblast growth factor-2 (FGF-2) is usually studied in regeneration of periodontal tissues. This protein has a potential to increase and to facilitate the revascularization, which become one of the targets to treat ulcers and bone fractures. In fact, animal studies have confirmed that FGF-2 can enhance the regeneration of periodontal tissues under local application (14-15). Among its numerous effects, FGF2 has been shown to be effective promoting endothelial cell proliferation and possessing angiogenic and mitogenic activities on mesenchymal stem cells from the periodontal ligament (16).

Until now, few studies have explored PICF modifications after mucositis treatment, leading to scarce knowledge about the biological peri-implant response for applied treatment $(17,18)$. In addition, no previous investigation has been conducted to evaluate the role FGF-2 in a peri-implant treatment protocol. Regenerative biomarker identification in the PICF can elucidate the local response to periimplant therapies, leading to early diagnosis and clinical strategies in implant dentistry. Therefore, the aim of the present research was to analyze the FGF-2 expression in PICF of patients undergoing supportive mucositis therapy.

\section{Material and methods}

This is a non-randomized controlled clinical trial approved by the Research Ethics Committee from Antônio Pedro University Hospital / Fluminense Federal University, under number 2.455.991. The clinical data was collected in the Implant Dentistry Department of Fluminense Federal University and the laboratory assays were carried out in the Clinical Research Unit of the Antonio Pedro University Hospital.

\section{Inclusion criteria}

As far as the authors know, this study included healthy patients, with and without previous history of periodontitis. The participants were partial edentulous patients with previous radiography showing the alveolar bone level around teeth, with an external hexagon implant installed for at least 1 year finished with fixed total Branemark's protocol prostheses in the mandible and who signed the free and informed consent form.

\section{Exclusion criteria}

The excluded participants were those with systemic diseases (diabetes, blood dyscrasias), smokers, and those who take resorptive drugs and hormones. Patients who underwent mouthwash, antibiotic, and/or anti-inflammatory therapy 3 months prior to the research and those diagnosed with periimplantitis or who underwent supportive peri-implant therapy 6 months prior research diagnosis were also excluded.

\section{Participants}

The participants consisted of all patients who attended the Implant Dentistry Department of the Fluminense Federal University from 2003 to 2016 and who had an external hexagon dental implant installed and finished with fixed total Branemark's protocol prostheses in the mandible. From a total of 
42 patients, 4 were excluded due to systemic diseases, 6 because of smoking habits, 3 due to a change of address, and 3 were diagnosed with peri-implantitis who were referred for specific treatment in the Implant Dentistry Department. Therefore, 26 total participants were selected for this study.

\section{Clinical examination and treatment}

A single investigator (J.P.G.C.), calibrated through the kappa-test, performed the clinical examination, sample collection, and treatment. The implant-supported prostheses were removed and all implants and peri-implant tissues were examined at three different times: Time 1 (initial clinical and radiographic exam/ diagnosis); Time 2 (15 days after initial treatment); Time 3 (21 days after the second treatment). The peri-implant clinical examination was performed on the mesial, distal, buccal, and lingual surfaces of each implant using a North Carolina periodontal probe (PCP-UNC 15, Hu-Friedy Manufacturing Inc., Chicago, IL, USA). In addition, the distance between the prostheses ridge and periimplant mucosa was evaluated by using a straight tip specimeter (Golgran- Millennium, São Paulo, SP, Brazil).

Peri-implant health and mucositis were diagnosed based on the parameters established by the 2017 World Workshop on the Classification of Periodontal and Peri-Implant Diseases and Conditions (4). According to the initial diagnosis (Time 1), the participants were separated into two groups: the control group, characterized by good peri-implant health for all implants, and the mucositis group, characterized by peri-implant mucositis for at least one implant. Based on the new diagnosis during re-evaluation (Times 2 and 3), the participants could be reassigned to the control or mucositis group throughout the study. Therefore, participants from mucositis group could be included in control group if the periimplant health conditions were recovered.

\section{Radiographic evaluation before implant placement}

It was performed in order to identify the presence or absence of alveolar bone resorption around teeth. The diagnosis of periodontitis history was based on Armitage (19) and it was part of the clinical protocol of the University.

\section{Radiographic evaluation during peri-implant diagnosis}

Another author (T.R.S.A.), as a single operator performed the digital radiographic examination around implant in order to identify the peri-implant bone level and possible peri-implanttis diagnosis. This exam consisted of periapical digital radiographs (Indicator Digital Shick Elite, KODAK RVG5100 Digital Radiography System - São José dos Campos, SP-Brazil) using a positioner (Indusbello Londrina, PR-Brazil) performed in the RX device (DABI ATLANTE Spectro 70x RX, Ribeirão Preto, SP-Brazil). For diagnostic reasons, the radiographic examination was performed on all participants at Time 1 . When participants were diagnosed with peri-implantitis, they were excluded from this study and referred to a supportive program in the Implant Dentistry Department. The physiological bone loss was characterized considering the normal bone loss of one millimeter during the first year after implant placement and of $0.2 \mathrm{~mm}$ per subsequent year according to the period of osseointegration (20). The crestal bone loss calculation was based on the difference between the radiographic examination at baseline (considering external hexagon implant placement at the bone level for all included implants) and the radiographic aspect during supportive therapy. From these parameters, when the total bone loss was higher than expected ( $1 \mathrm{~mm}$ in the first year and $0.2 \mathrm{~mm}$ in subsequent years under loading conditions) (20), the diagnosis was peri-implantitis, taking into account the pathologic bone loss.

\section{Treatment protocol}

All participants included in this study received the same treatment, regardless of their diagnosis. Ultrasonic scalers were used for calculus removal (Cavflex 6000 Dentflex ${ }^{\circledR}$, Ribeirão Preto, SP, Brazil). In the control group (health mucosae) the ultrasonic scalers was applied to remove calculus from prosthesis and supragingival calculus, which did not affect the mucosae health. Sodium air-abrasive polishing (JetlaxisUNO Schuster, Santa Maria, RS, Brazil) was used to remove the soft debris from the implant, prosthetic components, and fixed implant-supported prostheses (Figure 1). 
Time 1 - ultrasonic scaler + air polishing + mouthwash

twice a day with chlorhexidine digluconate $0.12 \%$ during

14 days (Perioxidin spray-Lacer), + prosthetic repair +

instruction on self-performed plaque removal

Time 2 (15 days after Time1) - ultrasonic scaler + air

polishing

Time 3 (21 days after Time2) - ultrasonic scaler + air

polishing

Figure 1. Summary of treatment protocol performed at each interval.

Participants received the same protocol because despite the calculus accumulation in peri-implant tissue or implant-supported prostheses, which need to be removed, there was observed the presence of peri-implant inflammation (mucositis) or absence of peri-implant inflammation (health mucosae).

Oral and written self-performed plaque control instructions were provided. Prosthetic adjustment was performed to allow hygiene access around implants (21).

All implant-supported fixed protocols were removed, cleaned, and polished with tungsten carbide drills (Série Ultra 079KFF - Dhpro - Paranaguá, Paraná - Brasil), finishing and polishing points (Kit PA10203Dhpro - Paranaguá, PR - Brasil), and replaced immediately. Prior to treatment, PICF was collected at the previously described intervals. The debris around the implants were removed with cotton pellets, and a paper tip filter (Maillefer - Dentsply, Petrópolis, RJ-Brazil) was inserted in to the periimplant crevicular region for 60 seconds and then immediately submerged in $400 \mu$ I PBS/ 1\% BSA (fetal serum bovine / bovine serum albumin) and stored at $-80^{\circ} \mathrm{C}$ (Froi Lab Ultra Low Temperature DW HL678S - São Paulo, SP - Brasil).

The site with the highest degree of disease for each participant was chosen for sample collection. In cases in which all peri-implant regions were healthy, the implant site nearest the midline underwent collection. Twenty-six samples were collected at each time point; 78 samples in total were collected throughout this research.

Fibroblast growth factor-2 levels in the peri-implant crevicular fluid

FGF-2 levels in the samples were determined by enzyme-linked immunosorbent assay (ELISA) using the Human FGF-basic ELISA kit (900-K08 - Peprotech, Rocky Hill, NJ, USA). Analyzes of the diluted samples were performed by following the manufacturer's recommendations. The readings were made in $110 \mu \mathrm{L}$ of the sample, with filters of $405 \mathrm{~nm}$ wavelength generated from a standard curve of concentrations. After mathematical conversion considering the dilution, the standard curve, and the dispersion graphic, the FGF-2 concentrations were defined in $\mathrm{pg} / \mu \mathrm{l}$.

\section{Statistical analysis}

Data processing and statistical analysis were performed using Prisma GraphPad software 6.0 (GraphPad Software, La Jolla, CA, USA). The distribution of the numerical variables was analyzed by the Shapiro-Wilk test. Student's or Mann-Whitney's t-test was applied in cases of normal or non-normal distribution, respectively. The chi-square test considered a significance level of $0.05 \%(p<0.05)$ in order to correlate the peri-implant mucositis with the clinical data of the nominal variables. The risk of developing peri-implant mucositis was correlated with the nominal variables using the odds ratio (OD), constructing a $95 \%$ confidence interval.

\section{Results}

Clinical results

From the total of 42 volunteers evaluated over 1 year, 26 were included in this research. There were $16(61.5 \%)$ men and $10(38.5 \%)$ women, with a mean age of $65.5 \pm 7.99$ years. At baseline (Time 1), there was no significant difference between the control group and the mucositis group regarding gender, age, and periodontitis history ( $p>0.05$ ) (Table 1$)$. During this primary diagnosis (Time 1$)$, participants were divided into 2 groups: Control $(n=8)$ and Mucositis $(n=18)$, showing no difference in plaque- 
accumulation, which was present in both groups, which demonstrates that mucositis was not clinically plaque-dependent $(p>0.05)$.

Table 1. Clinical aspects of all participants: Time 1.

\begin{tabular}{lccc}
\hline Parameters & Control $(\mathrm{N}=8 / \%)$ & Mucositis $(\mathrm{N}=18 / \%)$ & p-value $(\mathrm{OR} ; \mathrm{Cl})^{*}$ \\
\hline Gender & $3(37.5)$ & $13(72.2)$ & \\
$\quad$ Male & $5(62.5)$ & $5(27.8)$ & $0.10(0.23: 0.03-1.34)$ \\
$\quad$ Female & $67.75 \pm 2.1$ & $64.72 \pm 2.0$ & 0.38 \\
Age & $5(62.5)$ & $8(44.4)$ & $0.33(2.08: 0.37-11.48)$ \\
Periodontitis History & &
\end{tabular}

After initial treatment (15 days, Time 2 ) and final treatment (36 days from baseline, Time 3 ), the control group and mucositis group showed difference in the width of keratinized mucosa $(p=0.03)$ at Time 3 . The presence of a greater width of keratinized mucosa was significantly associated with healthy peri-implant sites (control group).

However, the transition of participants from mucositis group to control group was evident after initial supportive therapy, during Time 2 (control $=18$; mucositis $=8$ ), and at Time 3 (control=20; mucositis=6). After 36 days, the clinical mucositis incidence decreased from $70 \%$ to $23 \%$, showing significant improvement after primary treatment (Time 1) ( $p=0.003)$ (Figure 2).

\section{Clinical Evolution}

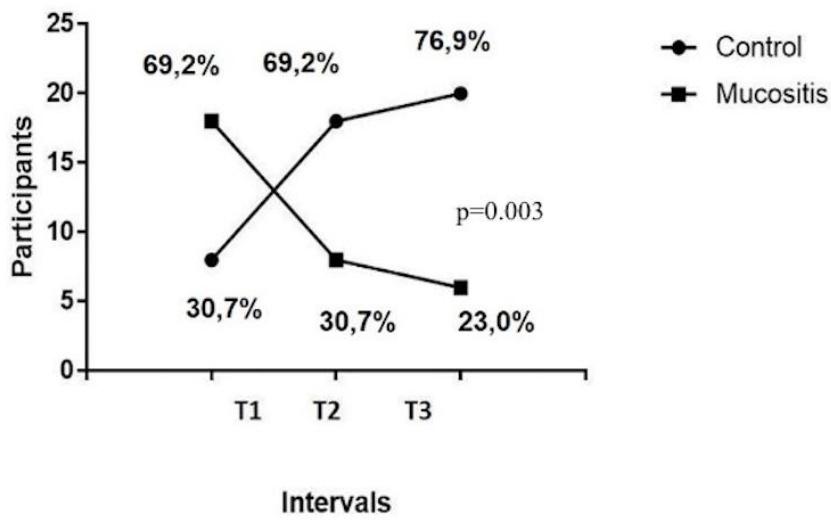

Figure 2. Clinical Evaluation from Time 1 to Time 3, after 36 days of mucositis treatment and supportive therapy $(p=0.03)$.

\section{Laboratory results (FGF-2 levels)}

Taking into account the comparison between the 2 groups throughout the 36 days (all treatment intervals), a statistically significant difference in FGF-2 levels was evident, with the higher FGF-2 levels in control group ( $p=0.01$ ) (Figure 3).

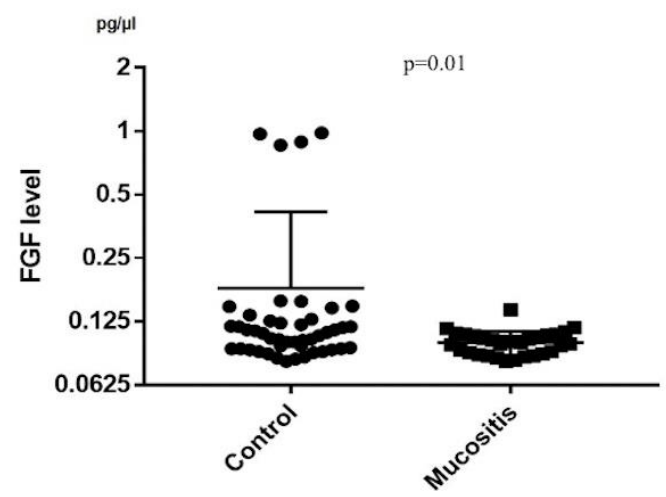

Figure 3. FGF-2 showed higher levels in the Control Group compared to the Mucositis Group, considering all analyzed intervals ( $p=0.01$ ) (Graphic in Log 2 scale). FGF-2 levels: $p g / \mu \mathrm{L}$ 
The analysis of the comparison among each interval (T1, T2, and $\mathrm{T} 3)$ within each group separately showed that in the Control Group there was no difference among each Time $(p=0.12)$. However, the increased levels of FGF-2 alongside treatment were evident. In contrast, in Mucositis Group there was a difference among each Time $(\mathrm{p}=0.007)$, with higher FGF-2 levels at T3 (Figure 4).
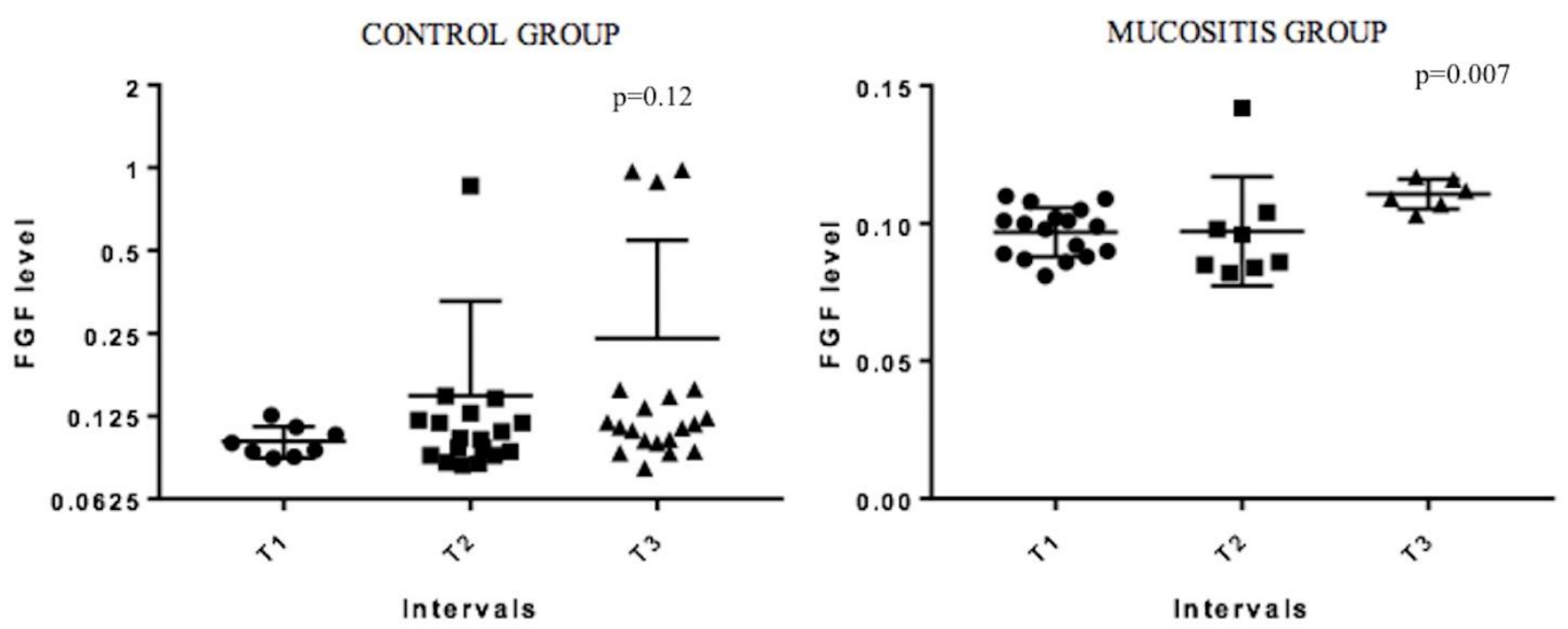

Figure 4. Intervals comparison within each group, showing significant increase of FGF-2 levels in Mucosistis Group ( $p=0.007$ ).

The comparison between the control and mucositis group at each interval showed no statistically significant difference in FGF-2 levels ( $p>0.05$ ). However, there was an evident elevation of FGF-2 levels in both groups throughout treatment (Figure 5).

\section{FGF2 X DIAGNOSIS}

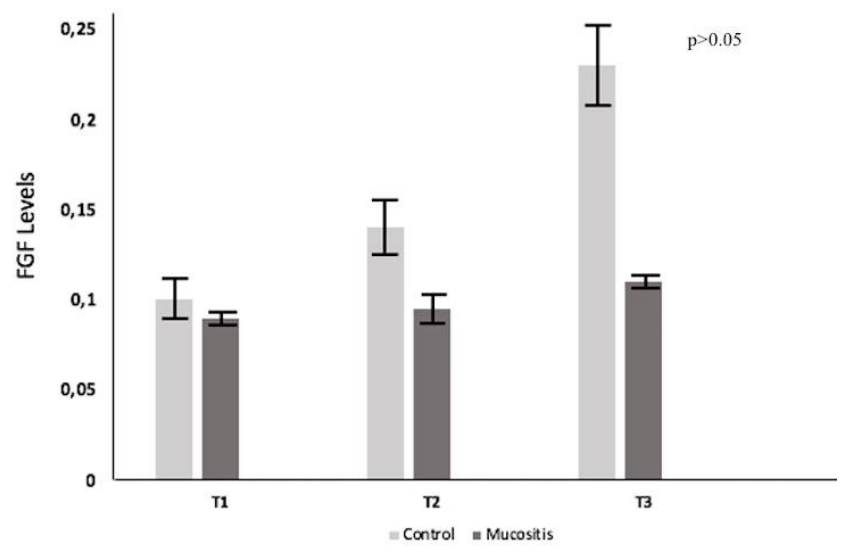

Figure 5. Comparison of FGF-2 levels among treatment intervals in both Groups. FGF-2 levels: pg/ $\mu$ l.

\section{Discussion}

Peri-implant mucositis, in fact, denotes the obvious precursor of peri-implantitis, then, the therapy of peri-implant mucositis should be considered a prerequisite for the prevention of periimplantitis (4).

Despite the number of therapies that have been clinically applied to treat peri-implant mucositis, very few studies $(17,21)$ have addressed the correlation of biological basis and clinical results after mucositis treatment. Therefore, taking into account the possible regenerative potential of FGF-2 in soft and hard tissues, the aim of the present study was to analyze FGF-2 expression in the peri-implant crevicular fluid of patients undergoing supportive mucositis therapy. Our main results showed that history of periodontitis can have no relationship with peri-implant mucositis presence; the smaller the range of keratinized mucosa the higher susceptibility of peri-implant mucositis; peri-implant mucositis was not clinically plaque-dependent; the supportive peri-implant therapy was effective for peri-implant health maintenance and peri-implant mucositis treatment; there was clinical-laboratory relationship 
between supportive peri-implant therapy and FGF-2 levels; healthy peri-implant sites were associated with elevated FGF-2 levels in PICF; FGF-2 levels increased throughout the mucositis treatment.

A total of 26 participants were included in this study. Our exclusion criteria were extremely restrictive for systemic diseases and smoking habits in order to exclude possible risk factors previously described for peri-implant disease development (3) that could influence treatment results. In addition, only the Branemark protocol prostheses supported by external hexagon implants were evaluated in order to focus on a specific implant type and implant-abutment connection.

Several authors have confirmed that periodontitis is a risk factor for peri-implant disease $(6,12,22)$. Since the first observations of Malmstrom et al (23), which described greater implant loss in a patient who presented rapidly progressive periodontitis, numerous clinical trials have studied the possible association between periodontitis and implant failure. Some of these studies showed that periodontal disease may cause a higher implant loss rate $(24,25)$, whereas others find no association between implant failure and a history of periodontitis $(22,26)$. In our study, there was no relationship between periodontitis history and the presence of peri-implant mucositis at all periods of treatment, emphasizing that periodontitis history can be not determinant for peri-implant disease development and implant failure. However, the long-term evaluation of these patients will indicate whether the previous history behaves as a risk indicator for peri-implant diseases or not. In addition, there is a set of factors possibly trigger this multifactorial disease.

The presence of a greater width of keratinized mucosa was significantly associated with healthy peri-implant sites. Our results showed that the smaller keratinized mucosa width the increased periimplant mucositis development. This result is supported by the research of Roos-Jansaker et al. (27), which demonstrated an association between the absence of keratinized gingiva and peri-implant mucositis. In a 2016 systematic review, Praskunas et al. (28) pointed to an adequate range of keratinized gingiva with at least $2 \mathrm{~mm}$. However, it was found that keratinized mucosa width has low influence on peri-implant tissue reaction if oral hygiene is absent (29).

Despite the concept that experimental peri-implant mucositis in humans is based on oral hygiene suspension for 21 days, this procedure was not applied in our research. However, the presence of visible plaque under implant-supported prostheses and surrounding the dental implants was evident during the clinical examination throughout of the period of analysis (36 days). Oral hygiene instruction, patient motivation, and prostheses redesign during supportive therapy treatment were not enough to prevent plaque accumulation. Still, the reduction of clinical signs of inflammation were observed after supportive therapy in the peri-implant mucositis group. This fact can suggest that the peri-implant inflammatory reaction is not only strictly associated with biofilm infection, but also with the individual's capacity of maintaining peri-implant health over imminent damage.

The effect of biofilm accumulation on the peri-implant mucosa has been described in many reports, indicating that bacterial deposits on implants induces inflammation in the peri-implant mucosa similar to the way dental plaque produces gingivitis (30). Experimental studies in humans became evident that bacterial biofilm accumulated during a period of 3 weeks exhibits a similar effect in teeth (gingivitis) and dental implants (peri-implant mucositis) (31). Heterogeneity of clinical signs during the development of gingivitis had already been previously noted by Loe et al. (32) and was indicated to be due to differences not only in the plaque volume but also in the microbial composition (33). However, it was observed that the inflammatory response is significantly stronger in the peri-implant mucosa compared to the gingiva (34). Nowadays, it is recognized that mucosae inflammation is dependent on host factors that modulate the inflammatory response to the bacteria presence (35), which is in accordance with our results, which clearly demonstrated different clinical inflammatory reactions under the presence of cumulative plaque. Until now, there is no evidence in the literature that a specific peri-implant disease exists as a unique entity with a specific etiology and pathogenesis. Immunological problems associated with peri-implant metabolism are part of the reason that explain why dental implants can be lost (36).

Despite the multifactorial etiology of peri-implant mucositis, very few studies have addressed its treatment $(37,38)$. A number of therapies have been used in application to peri-implant mucositis. Most of these therapies use non-invasive methods, including antiseptic agents $(11,39)$, the administration of antibiotics (40), the use of glycine powder air-polishing (41), or the use of sodium carbonate abrasive air-polishing (40). In general, non-surgical treatment (closed debridement) of peri-implant disease involves the mechanical removal of plaque and/or calculus from the surfaces of the implant, which has demonstrated to be effective in treating peri-implant mucositis (42).The adjunct use of antiseptic oral rinses in combination with non-surgical mechanical debridement improved the treatment outcome compared to the use of non-surgical mechanical debridement alone (43). In addition, histological results 
by Trejo et al. (44) showed minimal inflammation in groups treated by mechanical debridement. Sodium carbonate abrasive air-powder was demonstrated to be an effective treatment (17). Therefore, in our study, we adopted a non-invasive method as a supportive therapy by using mechanical debridement associated with sodium abrasive air polishing, gluconate chlorhexidine spray, and oral hygiene instruction.

Non-invasive treatment is considered the primary option to treat peri-implant mucositis due to the absence of peri-implant bone loss, which restricts tissue damage to the peri-implant mucosa. This treatment is based on the inflammatory response stabilization through debridement and chemistry agents (42). Our results clearly demonstrated significant improvement of the peri-implant condition under non-invasive therapy. Clinical evaluation (in both groups) after treatment demonstrated a significant transition of participants from the mucositis group to the control group after initial treatment. After 36 days under treatment, the incidence of peri-implant mucositis decreased from $70 \%$ to $23 \%$.

Clinically, supportive therapy established peri-implant health in most of the participants, and it was efficient in keeping healthy conditions in the control group. However, it is unclear how biological modification is conducted around implants during the treatment period. In fact, research studies attempt to understand peri-implant disease development through the response in the implant-bone interface. The peri-implant sulcular fluid (PISF) was shown as a promising medium for the detection of peri-implant activity (12). The analysis of the composition of the PISF is based on a non-invasive method to assess the inflammatory conditions of the peri-implant tissues. Therefore, in the present study, samples of PISF were collected during each interval of clinical examination and treatment in order to verify the periimplant tissue response after supportive therapy.

Several reports have described the use of cytokines as "signaling molecules" to be applied in the field of regenerative medicine, based on directed stimulation over proliferation and differentiation of stem cells. Among those cytokines, FGF-2 is gaining attention due to its capacity of maintaining multilineage potential of mesenchymal stem cells during its proliferation $(16,45)$. This potential of FGF2 became this protein a target for drug development and it has already been applied, with success, to treat a human intractable ulcer curing (Fiblast Spray; Kaken Pharmaceutical Co., Ltd.) for more than 4 years (46).

Until now, FGF-2 has not been studied in peri-implant mucositis development or treatment response in order to clarify the influence of possible regenerative potential over peri-implant tissues. We explored FGF-2 function by measuring this level after 3 different treatment intervals in healthy and mucositis peri-implant tissues in order to understand if the FGF-2 levels in peri-implant tissue have a relationship with mucositis development. The relationship between clinical peri-implant health and higher levels of FGF-2 in PISF became evident in our results. In addition, FGF-2 levels increased throughout the treatment in the mucositis group. However, we believe that despite elevated FGF-2 levels alongside the treatment in the mucositis group, this was not enough to promote a regenerative response in order to avoid peri-implant collapse. This fact suggests that the regenerative capacity in the mucositis group can be lower than in the control group.

In an inflammatory process, biochemical changes appear earlier than the clinical ones. Recent reports demonstrated that the reversibility of peri-implant mucositis, after 3 weeks of treatment, is only biochemical, which indicates that the clinical recovery takes a longer time to be detected (34). Taking into account the period of evaluation in this research, our FGF-2 findings suggest that peri-implant mucositis sites are still in the healing process and could possibly achieve higher FGF-2 levels in order to modify clinical signs of inflammation in a postponed treatment interval.

The effectiveness of supportive therapy was demonstrated clinically and biologically in our research, based on FGF-2 possible regenerative potential. However, future studies are necessary in order to explore the role of FGF-2 in peri-implant health and disease. It is important to determine the ideal interval to achieve and to sustain peri-implant health in all patients undergoing supportive therapy. The short interval of treatment proposed in our study has limitations for long-term clinical applications as well as the small and different sample size between groups. In addition, the detailed analysis of PICF could reveal other biomarkers for future treatment protocols.

\section{Conflict of interest}

All authors disclose no actual or potential conflict of interest including any financial, personal or other relationships with other people or organizations that could inappropriately influence (bias) their work. 


\section{Acknowledgment}

Authors are indebted with the individuals that enthusiastically participated in the research protocols involved in this study. In addition, authors thank to the whole team from the Clinical Research Unit, Associate Laboratory of Clinical Research in Dentistry and Implant dentistry Post-graduation that contribute for the laboratorial and clinical procedures.

\section{Resumo}

Este estudo teve como objetivo analisar os niveis de FGF-2 no fluido crevicular peri-implantar durante a terapia de suporte da mucosite. Vinte e seis participantes com prótese protocolo Branemark foram divididos em dois grupos: o grupo controle, caracterizado por saúde peri-implanter, e o grupo mucosite, apresentando diagnóstico de mucosite peri-implantar. Todos os participantes foram submetidos a exame clínico, análise radiográfica, retirada da prótese e terapia não invasiva periimplantar (debridamento mecânico associado à clorexidina 0,12\%) durante um periodo de 36 dias, dividido em três intervalos. Amostras de fluido crevicular peri-implantar foram coletadas em cada intervalo para análise dos níveis de FGF-2, por ensaio imunoenzimático. Os grupos controle e mucosite não apresentaram diferença nos parâmetros clínicos, exceto para mucosa queratinizada. Ao longo dos intervalos de tratamento, os participantes foram diagnosticados em diferentes grupos, indicando se a terapia não invasiva era ou não capaz de tratar a mucosite peri-implantar. Houve diferença significativa dos niveis de FGF-2 entre os grupos, sendo os níveis de FGF-2 maiores no grupo controle $(p=0.01)$. Após a terapia de suporte, o grupo com mucosite apresentou niveis de FGF-2 significativamente aumentados $(p<0.01)$ em comparação aos niveis iniciais. Após 36 dias de terapia de suporte, houve redução da mucosite peri-implantar de $70 \%$ para $23 \%$. Os resultados clínicos e laboratoriais mostraram uma correlação clara, uma vez que os níveis de FGF-2 aumentaram após 36 dias. 0 protocolo de terapia foi eficaz e promoveu uma reação regenerativa. 0 FGF-2 pode ser considerado um alvo futuro para 0 tratamento da mucosite peri-implantar. 


\section{References}

1 Smeets $R$, Henningsen $A$, Jung 0 , Heiland $M$, Hammächer $C$, Stein JM. Definition, etiology, prevention and treatment of peri-implantitis--a review. Head Face Med. 2014;3:10-34. doi: 10.1186/1746-160X-10-34.

2. Chrcanovic BR, Albrektsson T, Wennerberg A. Reasons for failures of oral implants. J Oral Rehabil. 2014;41:443-76. doi: 10.1111/joor.12157.

3. Lindhe J, Meyle J. Peri-implant diseases: Consensus report of the Sixth European Workshop on Periodontology. J Clin Periodontol 2008;35: 82-285. doi: 10.1111/j.1600-051X.2008.01283.x.

4. Heitz-Mayfield UA, Salvi GE. Peri-implant mucositis. J Periodontol. 2018;89(Suppl 1):S257-S266. doi: 10.1002/JPER.16-0488

5. Berglundh T, Armitage G, Araujo MG, Avila-Ortiz G, Blanco J, Camargo PM, et al. Peri-implant diseases and conditions: Consensus report of workgroup 4 of the 2017 World Workshop on the Classification of Periodontal and Peri-Implant Diseases and Conditions. J Clin Periodontol. 2018 Jun;45 Suppl 20:S286-S291. doi: 10.1111/jcpe.12957. PMID: 29926491.

6. Costa FO, Takenaka-Martinez S, Cota LO, Ferreira SD, Silva GL, Costa JE. Peri-implant disease in subjects with and without preventive maintenance: a 5-year follow-up. J Clin Periodontol. 2012;39:17383. doi: 10.1111/j.1600-051X.2011.01819.x.

7. Jepsen $S$, Berglundh $T$, Genco $R$, Aass AM, Demirel $K_{1}$ Figuero $E_{1}$ et al. Primary prevention of periimplantitis: Managing peri-implant mucositis. J Clin Periodontol. 2015;42:S152-S157. doi: 10.1111/jcpe.12369.

8. Al Ghazal L, O'Sullivan J, Claffey N, Polyzois I. Comparison of two different techniques used for the maintenance of peri-implant soft tissue health: a pilot randomized clinical trial. Acta Odontol Scand. 2017;75:542-549. doi: 10.1080/00016357.2017.1352101.

9. Armitage GC, Xenoudi P. Post-treatment supportive care for the natural dentition and dental implants. Periodontol 2000. 2016;71:164-184. doi: 10.1111/prd.12122.

10. Riben-Grundstrom C, Norderyd O, André U, Renvert S. Treatment of peri-implant mucositis using a glycine powder air-polishing or ultrasonic device: a randomized clinical trial. J Clin Periodontol. 2015;42:462-469. doi: 10.1111/jcpe.12395.

11. Zhang J, Ab Malik N, McGrath C, Lam 0. The effect of antiseptic oral sprays on dental plaque and gingival inflammation: A systematic review and meta-analysis. Int J DentHyg. 2018;6. doi: 10.1111/idh.12331.

12. Casado PL, Canullo L, Filardy A, Granjeiro JM, Barboza EP, Leite Duarte ME. Interleukins $1 \beta$ and 10 expressions in the peri-implant crevicular fluid from patients with the untreated peri-implant disease. Implant Dent. 2013;22:143-50. doi: 10.1097/ID.0b013e3182818792.

13. Javed F, Al-Hezaimi K, Salameh Z, Almas K, Romanos GE. Proinflammatory cytokines in the crevicular fluid of patients with peri-implantitis. Cytokine. 2011;53: 8-12. doi: 10.1016/j.cyto.2010.08.013

14. Murakami S, Takayama S, Kitamura M. Recombinant human basic fibroblast growth factor (bFGF) stimulates periodontal regeneration in class II furcation defects created in beagle dogs. J Periodontal Res. 2003;38:97-103.

15. Murakami S. Periodontal tissue regeneration by signaling molecule(s): what role does basic fibroblast growth factor (FGF2) have in periodontal therapy? Periodontol 2000. 2011;56:188-208. doi: 10.1111/j.1600-0757.2010.00365.x.

16. Cao $R$, Brakenhielm E, Pawliuk R. Angiogenic synergism, vascular stability and improvement of hind-limb ischemia by a combination of PDGF-BB and FGF-2. Nat Med. 2003;9:604-613.

17. Duarte $P M$, de Mendonça $A C$, Máximo MB, Santos VR, Bastos MF, Nociti FH. Effect of antiinfective mechanical therapy on clinical parameters and cytokine levels in human peri-implant diseases. J Periodontol. 2009;80:234-243. doi: 10.1902/jop.2009.070672 .

18. Severino VO, Beghini $M$, de Araujo MF, de Melo MLR, Rodrigues WF, de Lima Pereira SA. Expression of IL-6, IL-10, IL-17 and IL-33 in the peri-implant crevicular fluid of patients with periimplant mucositis and peri-implantitis. Arch Oral Biol. 2016;72:194-199. doi: 10.1016/j.archoralbio.2016.08.021

19. Armitage GC. Periodontal diagnoses and classification of periodontal diseases. Periodontol 2000. 2004;34:9-21.

20. Roos J, Sennerby L, Lekholm U, Jemt T, Albrektsson, T. A qualitative and quantitative method for evaluating implant success: a 5-year retrospective analysis of the Branemark implant. Int J Oral Max Impl. 1997;12:504-514. 
21. Zeza B, Pilloni A. Peri-implant mucositis treatments in humans: a systematic review. Ann Stomatol. 2012;3:83-89.

22. Karoussis I K, Kotsovilis S, Fourmousis I. A comprehensive and critical review of dental implant prognosis in periodontally compromised partially edentulous patients. Clin Oral Implants Res. 2007;18:669-679.

23. Malmstrom HS, Fritz ME, Timmis DP, Van Dyke TE. Osseo-integrated implant treatment of a patient with rapidly progressive periodontitis. Case report. J Periodontol. 1990;61:300-304.

24. Fardal 0, Linden GJ. Tooth loss and implant outcomes in patients refractory to treatment in a periodontal practice. J Clin Periodontol. 2008;35:733-738. doi: 10.1111/j.1600-051X.2008.01247.x.

25. Matarasso S, Rasperini G, lorio Siciliano V, Salvi GE, Lang NP, Aglietta M. A 10- year retrospective analysis of radiographic bone level changes of implants supporting single-unit crowns in periodontally compromised vs. periodontally healthy patients. Clin Oral Implants Res. 2010;21:898-903. doi: 10.1111/j.1600-0501.2010.01945.x.

26. Leonhardt A, Grondahl K, Bergstrom C, Lekholm U. Long-term follow-up of osseointegrated titanium implants using clinical, radiographic and microbiological parameters. Clin Oral Implants Res. 2002;13:127-132.

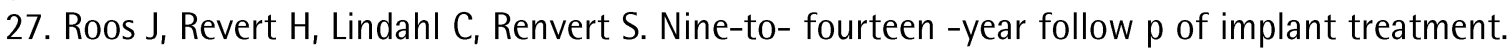
Part III: factors associated with peri-implant lesions. J Clin Periodontol. 2006;33:296-301.

28. Pranskunas $M$, Poskevicius $L$, Juodzbalys $G$, Kubilius $R$, Jimbo R. Influence of peri-Implant soft tissue condition and plaque accumulation on peri-implantitis: A systematic review. J Oral Maxillofac Res. 2016;9:e2.

29. Chiu YW, Lee SY, Lin YC, Lai YL. Significance of the width of keratinized mucosa on peri-implant health. JCMA. 2015;78:389-94. doi: 10.1016/j.jcma.2015.05.001.

30. Zitzmann NU, Berglundh T, Marinello CP. Experimental peri-implantmucositis in man. J ClinPeriodontol. 2001;28:517-523.

31. Pontoriero R, Tonetti MP, Carnevale G, Mombelli A, Nyman SR, Lang NP. Experimentally induced peri-implant mucositis. A clinical study in humans. Clin Oral Implants Res. 1994;5:254-259.

32. Loe $H$, Theilade $E$, Jensen SB. Experimental gingivitis in man. J Periodontol. 1965;36:177-87.

33. Theilade $E$, Wright $W H$, Jensen $S B$, Löe $H$. Experimental gingivitis in man. A longitudinal clinical and bacteriological investigation. J Periodontal Res. 1996;1:1-13.

34. Salvi GE, Aglietta M, Eick S, Sculean A, Lang NP, Ramseier CA. Reversibility of experimental periimplant mucositis compared with experimental gingivitis in humans. Clin Oral Implants Res. 2012;23:182-190. doi: 10.1111/j.1600-0501.2011.02220.x.

35. Meyer S, Giannopoulou C, Courvoisier D, Schimmel M, Muller F, Mombelli A. Experimental mucositis and experimental gingivitis in persons aged 70 or over. Clinical and biological responses. Clin Oral Implants Res. 2017;28:1005-1012. doi: 10.1111/clr.12912.

36. Albrektsson T, Canullo L, David C. Peri-implantitis: A complications of a foreign body or a manmade disease. Facts and fiction. Clin Implant Dent Relat Res. 2016;18:840-849.

37. Li JY, Wang HL. Biomarkers associated with peri-implant diseases. Implant Dent 2014;23:60711. doi: $10.1111 /$ cid.12427.

38. Hall J, Pehrson NG, Ekestubbe A, Jemt T, Friberg B. A controlled, cross-sectional exploratory study on markers for the plasminogen system and inflammation in crevicular fluid samples from healthy, mucositis and peri-implantitis sites. Eur J Oral Implantol2015;8:153- 166.

39. James $P$, Worthington HV, Parnell $C$, Harding $M$, Lamont $T$, Cheung $A$, et al. Chlorhexidine mouthrinse as an adjunctive treatment for gingival health. Cochrane Database Systematic Review. 2017;31:CD008676. doi: 10.1002/14651858.CD008676.

40. Ata-Ali J, Ata-Ali F, Galindo-Moreno P. Treatment of peri-implant mucositis: a systematic review of randomized controlled trials. Implant Dent 2015;24:13-8. doi: 10.1097/ID.0000000000000190.

41. Schwarz F, Becker K, Renvert S. Efficacy of air polishing for the non-surgical treatment of periimplant diseases: a systematic review. J ClinPeriodontol2015;42:951-959. doi: 10.1111/jcpe.12454.

42. Romanos GE, Javed F, Delgado-Ruiz RA, Calvo-Guirado JL. Peri-implant diseases: a review of treatment interventions. DentClin North Am. 2015;59:157-78. doi: 10.1016/j.cden.2014.08.002.

43. Mombelli A, Van Oosten MA, Schurch EJr, Lang NP. The microbiota associated with successful or failing osseointegrated titanium implants. Oral Microbiol. Immun1987;2:145-51.

44. Trejo PM, Bonaventura G, Weng D, Caffesse RG, Bragger U, Lang NP. Effect of mechanical and antiseptic therapy on peri-implant mucositis: an experimental study in monkeys. Clin Oral Implants Res. 2006;17:294-304. 
45. Rück A, Sylvén C. Therapeutic angiogenesis gains a leg to stand on. Mol Ther. 2008;16:808-810. 46. Kitamura $M$, Nakashima $K$, Kowashi $Y$, Fuji $T$, Shimauchi $H$, Sasano $T$, et al. Periodontal tissue regeneration using fibroblast growth factor-2: randomized controlled phase II clinical trial. PLoS One. 2008;3:e2611. doi: 10.1371/journal.pone.0002611.

Received: 07/10/2020 Accepted: 24/09/2021 